\title{
Maternal Compliance of Educational Intervention in Urban Slums in India
}

\author{
Shikha Chandrana ${ }^{\mathrm{a}}$, Darren Zinner ${ }^{\mathrm{b}}$
}

India contributes one fifth to the global burden of maternal mortality, which is a preventable health outcome. The government of India and the city legislators of Mumbai have been working to reduce the number of maternal and infant deaths in the urban poor communities by innovative governmental health programs and improving of the healthcare system, yet due to the low female literacy rate of $65 \%$ in the nation, population based programs combat only some aspects of the problem. The Society for Nutrition, Education and Health Action (SNEHA), a Mumbai based non-profit, aims to work with women in vulnerable communities through one on one home-based educational intervention through local community workers. Literature reviews on educational intervention and health promotion stressed on the success of community health worker programs. This paper aims to study the factors that lead to maternal compliance or non-compliance to educational intervention by the community workers in SNEHA. This was done through qualitative interviews with a random set of beneficiaries of the SNEHA's Maternal and Newborn Health promotion program. The beneficiaries were asked questions about compliance of medical checkups, vaccination, and other factors of maternal and infant health. The conclusions of the paper show that increased maternal compliance is related to better relationships with the community organizer, and the negative perceptions of the public medical providers leads to lower compliance of medical checkups.

Keywords: Maternal Health, Health Education, Health Compliance, Mumbai, India, Health education, Slum Health

\section{Introduction}

Maternal health has been defined as one of the major health concerns in developing nations and has been a part of both the Millennium Development Goals and the Sustainable Developing Goals. Globally, about 800 women die every day of preventable causes related to pregnancy and childbirth; 20 per cent of these women are from India. ${ }^{i}$ The improvement of maternal health has been slower in India than in other developing nations, even though the improvement of other health conditions like polio and chronic diseases has been much faster. India's goal is to lower maternal mortality to less than 100 per 100,000 live births but that is still far away despite its programmatic efforts and rapid economic progress over the past two decades. With a population of over a billion and decadal growth of $21 \%$, its maternal mortality ratio (MMR) is 301 (maternal deaths per 100,000 live births) in 2003. ${ }^{\text {ii }}$

Mumbai is a fascinating location for a case study in maternal health due to its large level of coexistent inequalities when it comes to women's health, the city boasts of world-class health facilities, yet struggles with equitable health distribution. The country's second largest city has a population 12.4 million, more than half of who live in slums. About onefifth of slum homes have a private toilet, only $31 \%$ of residents have completed 10 years of education, and the total fertility rate is below the replacement threshold at 1.9.iii The health care sector is characterized by a co-existence of medical systems and public and private providers. Public sector infrastructure includes teaching hospitals, specialist hospitals, general hospitals, maternity hospitals, and community-level health posts and dispensaries. Most urban health care across socioeconomic groups, including the disadvantaged, is privately provided. The sector is virtually unregulated and many practitioners are under qualified or lack formal training. ${ }^{\text {iv }}$

The $40 \%$ slum dwelling population, including the oftendiscounted migrant populations, face most trouble when it comes to using urban healthcare services as provided by urban health centers, which brings us to the major societal reason for the lack of accessed care, that is female education in urban poor regions. Female literacy is only $54 \%$, and women lack the empowerment to make decisions, including decision to use reproductive health services. As health services are governed at the state level, much depends on state leadership and management skills. Only $18 \%$ of 39,677 illiterate mothers had institutional deliveries compared to $86 \%$ of 39,677 mothers with 12 or more years of education; similar differences were observed in the use of skilled care at delivery and use of postnatal care. ${ }^{\mathrm{v}}$ The growth of rural areas in maternal health is comparable to the maternal health improvement of the urban poor that lags significantly behind the improvement of other urban populations. A hospital-based study conducted in New Delhi showed that the use of contraceptives among urban poor was $52 \%$, it is similar to contraceptive use in rural areas. ${ }^{\text {vi }}$ The burden of costs for maternal health care among the population living in slums is often significant. A study on expenditure on maternal health care showed that the poor living in slums in the city of Mumbai spent catastrophically on care, which is assumed to occur when the health expenditure exceeds a proportion (usually $40 \%$ ) of the total household income Yet, customs and tradition, as opposed to cost, was the most common reason given for delivering at home. The confluence of culture and medicine is extremely difficult in these populations that make the implementations of policy even harder. vii

The overall issues of maternal health cannot be solely put on the societal issues that exist within the urban poor populations; the governmental health policy too has not been able to make strides in the implementations of its goals. The strategies recommended by them have included risk screening during antenatal care. ${ }^{\text {viii }}$ Yet, despite the emphasis on antenatal care by the Government, about half of the pregnant mothers still do not complete three antenatal visits. The Indian publichealth system is fraught with basic problems, there is no system of accrediting health facilities or evaluating functionality of health facilities at the state or national level. The government spends only about $0.9 \%$ of gross domestic product on health services, one of the lowest in the world. The health program 
contributed an additional fund of US\$ 600 million, US\$ 300 million of which went to maternal health, in the span of 12 years. However, during these 12 years, there were about 300 million new births in India, giving an average of additional US\$ 1 per birth, which is insufficient to really change maternal care provided to pregnant women. ${ }^{\text {ix }}$

The lack of focus on maternal health can be a combination of multiple societal and policy factors that have done little to improve the condition of women in India.

This study analyzes on the work of the Society of Nutrition, Education and Health Action (SNEHA), a Mumbai-based nonprofit organization that focuses on the improvement of women's health in the city, with a focus on their Maternal and Neonatal Health Program. The MNH program by SNEHA focuses to improve both societal and governmental policy aspects of maternal health in the city to improve the health outcomes of the women in the city.

SNEHA's approach can be divided into the following two aspects:

Working with the public healthcare system: works with public hospitals to map and establish referral networks and promote appropriate care for women with potential complications. Educating vulnerable slum communities: Through home visits, community meetings, and formation of community health committees, SNEHA engages pregnant mothers and their families to promote utilization of public services for mothers to improve their knowledge of anteand post-natal danger signs, maternal nutrition, appropriate child feeding practice, and family planning method.

Analysis of the progress in the health education programs was done to determine what factors work best in the overall improvement of health literacy as well as what aspects of public hospitals are those in need of most improvement and the role of non-governmental offices in bridging the gap between implementation by the national ministries and goals.

\section{Methods}

Informal conversations were held with 3-4 of them to understand their perceived issues with maternal compliance, the community's power to make change and be involved with education. After this step, a total of 150 beneficiaries, mothers who were a part of SNEHA's educational and referral system, were identified by the community workers based on their experience as being compliers or non-compliers, out of which 35 beneficiaries were picked at random by generating random numbers from a computer program, for the qualitative interview. The level of compliance was based on rate of attendance, presence and enthusiasm about adoption of SNEHA's methods, communication rate with organization and its volunteers.

\section{Interviews}

The in person qualitative interview lasted for between 2030 mins. The interview was voluntary with the ability to terminate the interview at any point during the process, no incentive was provided to be a part of the study to ensure lack of coercion. The interview focuses on the following major themes: familial background, compliance information, experience with SNEHA, experience with the medical system and future expectations. The participants described the benefit of the knowledge gained by the program, social factors that come in the way of health outcomes, reasons, if any, of being unable to follow the programs educational guidelines. The responses were then analyzed for themes. Interviews were the most ideal method for this study, as it was a way to get the large depth of reasons of compliance or non-compliance to the interventions of the organization. It was a way to get feedback on the organization on a person-to-person level and identifying unique as well as common social themes in health care access barriers. Since not all the women were at an educational level to do surveys or written exercises, a conversation was the best way to develop a connection with them.

The consent was provided to them verbally, since there were varying levels of reading ability. The entire informed consent was explained and their consent and preference of recording was recorded on a phone device.

\section{Post Transcription Analysis}

Once the process of transcription was completed, themes of family history, compliance, experience with SNEHA, experience with hospital and future expectations. Yes or no responses were coded 1 and 2 respectively and analyzed through statistical analyses. Qualitative answers about patient experience and expectations were analyzed in a broad theme format.

\section{Results}

The results are based on 34 interviews conducted in the summer of 2016. The tables and text below show the information on the usage of medical care during pregnancy as well as the level of compliance of medical information provided by SNEHA's community organizers.

\section{Descriptive statistics:}

The information coded in Table 1 provides information on basic demographic details of the women interviewed for this study.

\begin{tabular}{llllll} 
Table 1: Descriptive Statistics & & & & & \\
\hline & $\mathrm{N}$ & Mean & SD & Min & M ax \\
\hline $\begin{array}{l}\text { Number of Family Members } \\
\text { Number of Children }\end{array}$ & 34 & 5.15 & $(1.60)$ & 3 & 8 \\
(1- first birth) & 34 & 1.97 & $(1.03)$ & 1 & 5 \\
\hline
\end{tabular}

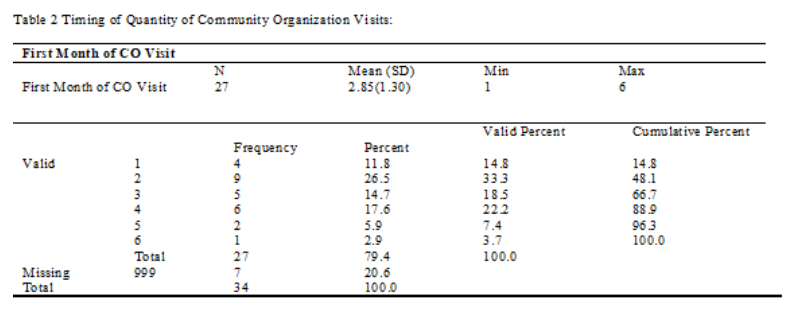

The average first month of the Community Organizer (CO) visit was 2.85 months, with $33.3 \%$ of the respondents saying that they were first visited by the $\mathrm{CO}$ in the $2^{\text {nd }}$ month of their pregnancy. Overall, $66.6 \%$ of the respondents met the SNEHA guideline and had first been visited by the $\mathrm{CO}$ before the end of their first trimester. Nearly $90 \%$ had been visited by the end the $4^{\text {th }}$ month. 


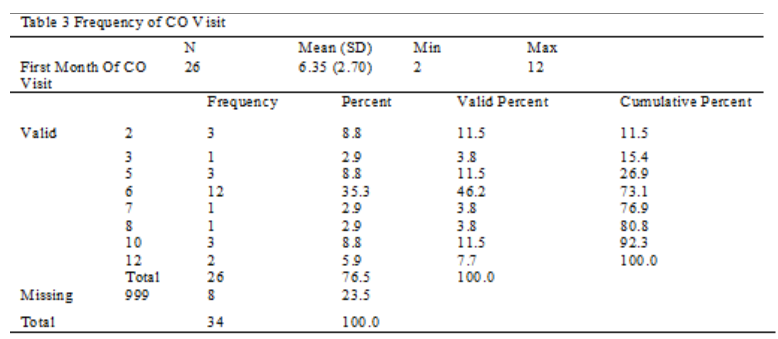

$46.3 \%$ of the respondents were visited by the $\mathrm{CO}$ about 6 times during their pregnancy, with $26.8 \%$ of the respondents visited by the $\mathrm{CO}$ less than 6 times, and $26.8 \%$ visited by the $\mathrm{CO}$ more than 6 times. Based on calculations of the timing and frequency of reported visits, respondents implied they were visited an average of about once a month with 0.98 visits per month.

\section{Timing of Quantity of Hospital Visits:}

\begin{tabular}{|c|c|c|c|c|c|}
\hline \multirow{2}{*}{\multicolumn{2}{|c|}{$\begin{array}{l}\text { First Month of } \\
\text { Hospital V isit }\end{array}$}} & $\mathrm{N}$ & Mean (SD) & $\operatorname{Min}$ & $\operatorname{Max}$ \\
\hline & & 25 & $3.72(2.11)$ & 0 & 8 \\
\hline \multirow[t]{10}{*}{ Valid } & 0 & $\begin{array}{l}\text { Frequency } \\
1\end{array}$ & $\begin{array}{l}\text { Percent } \\
2.9\end{array}$ & $\begin{array}{l}\text { Valid Percent } \\
4.0\end{array}$ & $\begin{array}{l}\text { Cumulative } \\
\text { Percent } \\
4.0\end{array}$ \\
\hline & 1 & 1 & 2.9 & 4.0 & 8.0 \\
\hline & 2 & 5 & 14.7 & 20.0 & 28.0 \\
\hline & 3 & 8 & 23.5 & 32.0 & 60.0 \\
\hline & 4 & 3 & 8.8 & 12.0 & 72.0 \\
\hline & 5 & 2 & 5.9 & 8.0 & 80.0 \\
\hline & 6 & 1 & 2.9 & 4.0 & 84.0 \\
\hline & 7 & 2 & 5.9 & 8.0 & 92.0 \\
\hline & 8 & & 5.9 & & 100.0 \\
\hline & Total & 25 & 73.5 & 100.0 & \\
\hline Missing & 999 & 9 & 26.5 & & \\
\hline Tota1 & & 34 & 100.0 & & \\
\hline
\end{tabular}

Beyond the at-home visits from the community organization, it is important for pregnant women to regularly see a physician for proper prenatal care and checkups. Government recommendations made by the Central department of health suggest that this care should start before the first trimester ${ }^{\mathrm{x}}$ and continue till the mother gives birth, with at least one or two follow ups in the first month post-delivery, depending on if the delivery was a C-section. According to their requirements, an expectant mother should make at least 4 visits for prenatal care, with the recommendation of weekly visits between week 4 and 28 and every two weeks after that. ${ }^{\mathrm{xi}}$ In our dataset, the first month of medical visit for the 34 beneficiaries was 3.72 months, or the beginning of the second trimester, slightly under the formal recommendation of at least the $4^{\text {th }}$ month. Most respondents $(64 \%)$ received their first check up between their $2^{\text {nd }}$ and $4^{\text {th }}$ month which is the recommended time frame for beginning of medical checkups for pregnancy, with $32 \%$ of the respondents saying that they first visited the hospital in the $3^{\text {rd }}$ month of their pregnancy. However, $20 \%$ of the respondents started getting regular checkups between their $6^{\text {th }}$ to $8^{\text {th }}$ month, which is considered a late-start on their prenatal care.

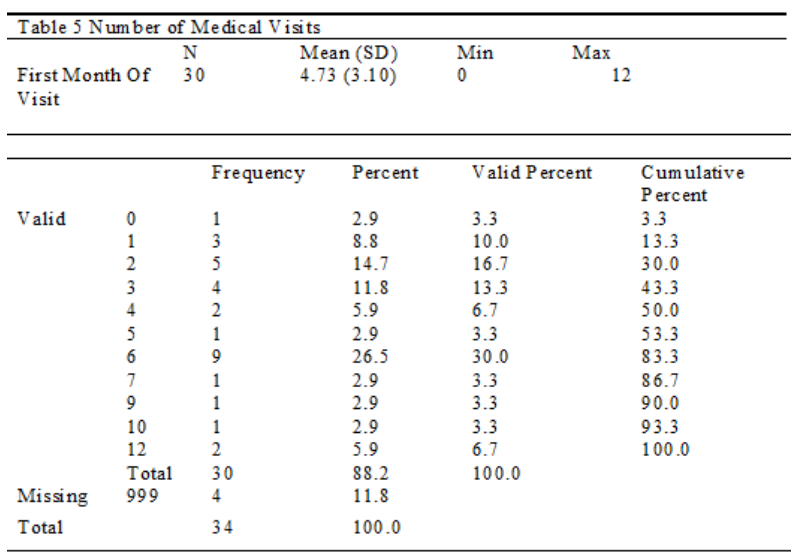

Among the participants in this study, the average number of hospital visits for the beneficiaries was 4.73 visits slightly higher than the government requirement but below the recommendation. The standard deviation of this average was 3.10 months which has a median range of 1-6 visits, which is a very large range, but the entire range exists below the recommendation.

Based on calculations of the timing and frequency of reported visits, respondents implied they visited the hospital an average of about once per month with 0.98 visits per month, which is the same as the number of $\mathrm{CO}$ visits per month.

\begin{tabular}{|c|c|c|c|c|}
\hline & & Count & $\begin{array}{l}\text { Table Total N } \\
q_{0}\end{array}$ & $\begin{array}{l}\text { Table Valid } \mathrm{N} \\
0 \%\end{array}$ \\
\hline \multirow{3}{*}{$\begin{array}{l}\text { At least one } \\
\text { Hospital Visit }\end{array}$} & Yes & 34 & $100.0 \%$ & $100.0 \%$ \\
\hline & & 0 & & \\
\hline & Subtotal & 34 & $100.0 \%$ & $100.0 \%$ \\
\hline \multirow{3}{*}{ Hospital Delivery } & Yes & 30 & $88.2 \%$ & $88.2 \%$ \\
\hline & & 4 & $11.8 \%$ & $11.8 \%$ \\
\hline & Subtotal & 34 & $100.0 \%$ & $100.0 \%$ \\
\hline \multirow{2}{*}{$\begin{array}{l}\text { First Check Up } \\
\text { before } 3^{\text {rd }} \text { Month }\end{array}$} & Yes & 13 & $38.2 \%$ & $50.0 \%$ \\
\hline & $\begin{array}{l}\text { No } \\
\text { Subtotal }\end{array}$ & $\begin{array}{l}13 \\
26\end{array}$ & $\begin{array}{l}38.2 \% \\
77.5 \%\end{array}$ & $50.0 \%$ \\
\hline \multirow{3}{*}{$\begin{array}{l}\text { Follow Up after } \\
\text { Pregnancy }\end{array}$} & Yes & 0 & $0.0 \%$ & $0.0 \%$ \\
\hline & & 34 & $100.0 \%$ & $100.0 \%$ \\
\hline & Subtotal & 34 & $100.0 \%$ & $100.0 \%$ \\
\hline \multirow{3}{*}{$\begin{array}{l}\text { At least Six Medical } \\
\text { Checks }\end{array}$} & Yes & 13 & $38.2 \%$ & $48.1 \%$ \\
\hline & & 14 & $41.2 \%$ & $51.9 \%$ \\
\hline & Subtotal & 27 & $79.4 \%$ & $100.0 \%$ \\
\hline Number of & Less than 6 visits & 7 & $20.6 \%$ & $26.9 \%$ \\
\hline Community & 6 or more visits & 19 & $55.9 \%$ & $73.1 \%$ \\
\hline Organizer Visits & Subtotal & 26 & $76.5 \%$ & $100.0 \%$ \\
\hline
\end{tabular}

In addition to the time and frequency of $\mathrm{CO}$ and prenatal visits, SNEHA has made several recommendations about the birth process to ensure safety, including hospital delivery and postnatal follow-up.

All 34 participants had at least one hospital visit, while 30 $(88.2 \%)$ gave birth in the hospital. As noted above, exactly half of the respondents had a checkup within the $1^{\text {st }}$ trimester. Surprisingly, none of the respondents had any medical follow ups with a primary care physician after pregnancy. Lastly, $51.9 \%$ of the respondents did not have at least 6 medical checkups during their pregnancy with $48.1 \%$ had less than 6 checkups. 


\begin{tabular}{|c|c|c|c|c|}
\hline & & Count & $\begin{array}{l}\text { Table Total N } \\
0 \%\end{array}$ & $\begin{array}{l}\text { Table Valid N } \\
0 \%\end{array}$ \\
\hline $\begin{array}{l}\text { At least one } \\
\text { Hospital Visit }\end{array}$ & $\begin{array}{l}\text { Yes } \\
\text { No } \\
\text { Subtota1 }\end{array}$ & $\begin{array}{l}34 \\
0 \\
34\end{array}$ & $\begin{array}{l}100.0 \% \\
0.0 \% \\
100.0 \%\end{array}$ & $\begin{array}{l}100.0 \% \\
0.0 \% \\
100.0 \%\end{array}$ \\
\hline Hospital Delivery & $\begin{array}{l}\text { Yes } \\
\text { No } \\
\text { Subtota1 }\end{array}$ & $\begin{array}{l}30 \\
4 \\
34\end{array}$ & $\begin{array}{l}88.2 \% \\
11.8 \% \\
100.0 \%\end{array}$ & $\begin{array}{l}88.2 \% \\
11.8 \% \\
100.0 \%\end{array}$ \\
\hline $\begin{array}{l}\text { First Check Up } \\
\text { before } 3^{\text {rld Month }}\end{array}$ & $\begin{array}{l}\text { Yes } \\
\text { No } \\
\text { Subtota1 }\end{array}$ & $\begin{array}{l}13 \\
13 \\
26\end{array}$ & $\begin{array}{l}38.2 \% \\
38.2 \% \\
76.5 \%\end{array}$ & $\begin{array}{l}50.0 \% \\
50.0 \% \\
100.0 \%\end{array}$ \\
\hline $\begin{array}{l}\text { Follow Up after } \\
\text { Pregnancy }\end{array}$ & $\begin{array}{l}\text { Yes } \\
\text { No } \\
\text { Subtota1 }\end{array}$ & $\begin{array}{l}0 \\
34 \\
34\end{array}$ & $\begin{array}{l}0.0 \% \\
100.0 \% \\
100.0 \%\end{array}$ & $\begin{array}{l}0.0 \% \\
100.0 \% \\
100.0 \%\end{array}$ \\
\hline $\begin{array}{l}\text { At least Six Medical } \\
\text { Checks }\end{array}$ & $\begin{array}{l}\text { Yes } \\
\text { No } \\
\text { Subtotal }\end{array}$ & $\begin{array}{l}13 \\
14 \\
27\end{array}$ & $\begin{array}{l}38.2 \% \\
41.2 \% \\
79.4 \%\end{array}$ & $\begin{array}{l}48.1 \% \\
51.9 \% \\
100.0 \%\end{array}$ \\
\hline $\begin{array}{l}\text { Number of } \\
\text { Community } \\
\text { Organizer Visits }\end{array}$ & $\begin{array}{l}\text { Less than } 6 \text { visits } \\
6 \text { or more visits } \\
\text { Subtotal }\end{array}$ & $\begin{array}{l}7 \\
19 \\
26\end{array}$ & $\begin{array}{l}20.6 \% \\
55.99 \% \\
76.5 \%\end{array}$ & $\begin{array}{l}26.9 \% \\
73.1 \% \\
100.0 \%\end{array}$ \\
\hline
\end{tabular}

Medication compliance measures were based on respondents regularly taking their iron and calcium supplements while pregnant as advised by the SNEHA community organizers. $51.7 \%$ completely or mostly complied taking their supplements during pregnancy and $48.3 \%$ were non-compliant (did not take or stopped taking) with their supplements before recommended by a medical provider or SNEHA community organizers.

Breastfeeding compliance was counted as yes if the beneficiary said that they exclusively breastfed the infant till the age of 6 months and then began weaning them off breast milk. In these questions it was made extremely clear that when exclusive breastfeeding was counted, it included no outside food, water or milk provided to the infant at that time. $68.8 \%$ of the respondents saying that they complied and $31.3 \%$ said they did not. The ones who were counted as non-compliant included those who did not breastfeed their child at all as well as those who prematurely stopped breastfeeding.

Vaccination compliance was counted as yes if the respondent said that they followed the entire vaccination schedule for the infant post birth till the age the child was at the time of the interview, and no if there they said they did not completely follow the vaccination schedule. $88.2 \%$ of the respondents saying that they complied completely with the vaccination schedule.

Cultural compliance in this case was based on the beneficiary following orders by medical practioners or SNEHA community organizers. To not follow cultural practices deemed unsafe for the infant. Practices deemed unsafe for the infant are application of ' $\mathrm{kohl}$ '/charcoal on the eyes of the infant which is known to cause eye infection in infants, application of oil on infants, massages that may lead to internal injuries to the newborn, using herbal medicines which are not recommended for infants before starting on food. $81.3 \%$ of the respondents said they did not comply to orders by SNEHA and its community organizers while $18.8 \%$ said they did listen to those orders and did not continue any harmful cultural practices.

\section{Factors are Associated with Non-Compliance}

As outlined in the methodology section, several hypotheses can help explain why participants did not adhere to SNEHA and CO recommendations. In these sections, each of the compliance factors is compared against demographic and visit frequency to identify patterns. Because of the very small sample size, no tests of statistical significance were conducted. i) Medication

\begin{tabular}{lllllll}
$\begin{array}{l}\text { Medication } \\
\text { Compliance }\end{array}$ & No. & $\begin{array}{l}\text { Avg. month of } \\
\text { CO visit }\end{array}$ & $\begin{array}{l}\text { Avg.no of } \\
\text { family }\end{array}$ & Avg. no of kids & No. of CO visit \\
\hline & Yes & 16 & 2.6 & 5.35 & 1.62 & 7.69 \\
& No & 14 & 3.16 & 5.12 & 2.42 & 4.66 \\
& $\begin{array}{l}\text { Did not } \\
\text { say }\end{array}$ & 4 & 3 & 4.25 & 1.75 & 5.75 \\
\hline
\end{tabular}

The respondents who complied had an average of 7.69 community organizer visits, while the ones who did not had an average of 4.66 visits, non-compliers had a lot fewer visits than compliers. The first month of $\mathrm{CO}$ visit for compliers (2.6 months) was also earlier than that of non-compliers (3.16 months).

ii) Breastfeeding

\begin{tabular}{lllllll}
$\begin{array}{l}\text { Breastfeeding } \\
\text { Compliance }\end{array}$ & No. & $\begin{array}{l}\text { avg. month of } \\
\text { CO visit }\end{array}$ & $\begin{array}{l}\text { avg. no of } \\
\text { family }\end{array}$ & Avg. no of kids & No. of CO visit \\
\hline & Yes & 22 & 2.67 & 5 & 1.77 & 6.56 \\
& no & 10 & 3.125 & 5.6 & 2.3 & 6.5 \\
& did not say & 2 & 4 & 4.5 & 2.5 & 4 \\
\hline
\end{tabular}

First month of CO visit for compliers (2.67 months) was earlier than that of non-compliers (3.12 months). The compliers had fewer children in the household than non-compliers (1.77 vs. 2.3 kids, respectively). Similarly, non-compliers had slightly larger families (5 family members for compliers vs. 5.6 for non-compliers).

iii) Vaccination

\begin{tabular}{cllllll}
$\begin{array}{l}\text { Vaccination } \\
\text { Compliance }\end{array}$ & No. & $\begin{array}{l}\text { Arg. month } \\
\text { of CO visit }\end{array}$ & $\begin{array}{l}\text { Arg. no of } \\
\text { family }\end{array}$ & $\begin{array}{l}\text { Arg. no of } \\
\text { kids }\end{array}$ & $\begin{array}{l}\text { No. of } \\
\text { CO risit }\end{array}$ \\
\hline & Yes & 30 & 3.67 & 6.75 & 2.75 & 7 \\
No & 4 & 2.75 & 6.26 & 1.86 & 6.26 \\
\hline
\end{tabular}

The respondents who complied had an average of 7 community organizer visits while the ones who did not had an average of 6.26 visits. The compliers had an average of 2.75 kids and 6.75 family members while the non-compliers had 1.86 kids and 6.36 family members on an average. Thus, more number of children leads to higher vaccination compliance since compliers had 2.75 children and the non-compliers 1.86 .

\begin{tabular}{|c|c|c|c|c|c|c|}
\hline $\begin{array}{l}\text { Cultural } \\
\text { Compliance }\end{array}$ & & No. & $\begin{array}{l}\text { Arg. month of CO } \\
\text { visit }\end{array}$ & $\begin{array}{l}\text { Avg. no of } \\
\text { family }\end{array}$ & $\begin{array}{l}\text { Avg. no of } \\
\text { kids }\end{array}$ & No. of $\mathrm{CO}$ visi \\
\hline & Yes & 6 & 2.33 & 4.83 & 1.83 & 7.2 \\
\hline & No & 26 & 2.818 & 53 & 2 & 5.3 \\
\hline & Did not say & 2 & 4 & 4 & 2 & 3.5 \\
\hline
\end{tabular}

The respondents who complied had an average of 7.2 community organizer visits, while the ones who did not had an average of 5.3 visits, thus non-compliers had a lot fewer visits than compliers. The first month of CO visit for compliers (2.3 months) was approximately two weeks ( 0.52 months) earlier than that of non-compliers. While both groups had similar sized families ( 1.83 vs. 2.0 children), non-compliers had more family members in their household (5.3) than those who did not perform any culture practices (4.83). The number of $\mathrm{CO}$ visits per month for cultural compliers were more than the visits per month for non-compliers (1.02 visits/month vs. 0.8 visits per month). 


\begin{tabular}{|c|c|c|c|c|c|}
\hline First check up & & $\begin{array}{l}\text { Avg. month } \\
\text { of } \mathrm{CO} \text { risit }\end{array}$ & $\begin{array}{l}\text { Avg.no of } \\
\text { fn mily }\end{array}$ & $\begin{array}{l}\text { Avg. no of } \\
\text { kids }\end{array}$ & No. of $\mathrm{CO}$ visit \\
\hline 0.2 & 7 & 1.81 & 5 & 2.14 & 6.4 \\
\hline $3-4$ & 11 & 3.11 & 5.3 & 1.7 & 6.5 \\
\hline $5-7$ & 5 & 3.75 & 4.2 & 2 & 6.75 \\
\hline $8-9$ & 2 & 5 & 6.5 & 4 & 6 \\
\hline
\end{tabular}

Data regarding the timing of a medical checkup with a physician shows a consistent relationship with initiating contact with the SNEHA community organizer. The respondents who had their first visit in the first 2 months had their first $\mathrm{CO}$ visit in the $1.81^{\mathrm{st}}$ month of pregnancy, with an increase in the first month of CO visit with an increase in the first visit to a hospital provider, the ones who visited the hospital in the $8^{\text {th }}$ or $9^{\text {th }}$ month, did not have their first CO visit until the $5^{\text {th }}$ month. Other relationships were inconsistent.

\begin{tabular}{|c|c|c|c|c|c|}
\hline $\begin{array}{l}\text { no of medical } \\
\text { check ups }\end{array}$ & & $\begin{array}{l}\text { Avg. month of } \\
\text { CO visit }\end{array}$ & $\begin{array}{l}\text { Avg. no of } \\
\text { family }\end{array}$ & $\begin{array}{l}\text { Avg. no of } \\
\text { kids }\end{array}$ & No. of $\mathrm{CO}$ risit \\
\hline $9-12$ & 4 & 1.67 & 4.5 & 1.75 & 8 \\
\hline $6-8$ & 10 & 2.78 & 5 & 1.7 & 7.42 \\
\hline $3-5$ & 7 & 3.75 & 5.7 & 2.85 & 6.6 \\
\hline 0.2 & 9 & 3.125 & 4.89 & 1.89 & 4.6 \\
\hline
\end{tabular}

As expected, the number of medical checkups was related with early and frequent contact with the CO. The respondents who had 9-12 checkups had their first $\mathrm{CO}$ visit in the $1.67^{\text {st }}$ month of pregnancy, with those who had $0-5$ visits did not have their first $\mathrm{CO}$ visit until the between the $3^{\text {rd }}$ and $3.5^{\text {th }}$ month. Similarly, respondents who had 9-12 medical provider checkups also had most number of visits by a community organizer, which were an average of 8 visits, the number of medical provider checkups reduced with the reduction in the average number of $\mathrm{CO}$ visits.

\section{$\underline{\text { Sensitivity Analysis }}$}

Analyses were conducted to compare the differences in the compliance percentages between first birth mothers and mothers who were having their second or further births. There were 14 mothers in the group that were in their first pregnancy and 20 mothers who had already had a previous child before they were a part of the intervention with the organization. For medication, $66.67 \%$ of first birth responders complied in contrast to the $44.44 \%$ of second or further birth mothers. In the case of breastfeeding and vaccination as well, first birth mothers complied more than second or further birth mothers, with $71.43 \%$ breastfeeding first birth compliers (vs. $66.67 \%$ second or more birth compliers) and $92.86 \%$ first birth vaccination compliance (vs. $85 \%$ second or more birth compliers). This overall improved first birth compliance was not seen in issues of cultural compliance since only $15 \%$ of first birth mothers stopped practicing harmful cultural practices in comparison with the $21.05 \%$ second or more birth mothers.

Sensitivity analyses were conducted to compare all the data in relation to first birth mothers and second time or more mothers. Overall no significant differences were found between compliance. Some minor notable results were that overall first birth compliers had more visits that second or more birth compliers, but so were the visits for first birth noncompliers in comparison to second or more birth noncompliers. Culturally compliant first birth compliers had a lot more CO visits (9 visits) vs. all other sections of first birth and second or more birth compliers.

\section{Qualitative Analysis of Interviews}

Qualitative data provides the beneficiary a way to explain their experience with the organization and the medical system providing comprehensive analysis of their experience. The responses of the beneficiaries were analyzed based on themes. One respondent could provide multiple themes in her responses thus the number of times a theme appeared could be more than the number of respondents in some cases. Some of the themes that emerged were bad quality care in health centers, lack of familial support in compliance and importance of SNEHA's organizers.

Perception of most valuable information by SNEHA

The following table tracks what beneficiaries determine as the most valuable information they got from the community organizers during their educational visits prenatally.

\begin{tabular}{|c|c|c|}
\hline Theme & Frequency & Quotes \\
\hline Nurrition & 20 & $\begin{array}{l}\text { "She asked me to eat } 3-4 \text { times a day and rest more, which I did. I } \\
\text { did not getany rest the first time. }\end{array}$ \\
\hline $\begin{array}{l}\text { Medical visits and } \\
\text { Hospital } \\
\text { Information }\end{array}$ & 11 & $\begin{array}{l}\text { "I did not know where the hospitals were and where to get deline ry } \\
\text { done. I an new here so she helped with that." }\end{array}$ \\
\hline Pre-natal lifes tyle & 9 & $\begin{array}{l}\text { "She told us to prepare before the delivery and have a bag of things } \\
\text { that we wolld need ready before hand. We should leep clothes. } \\
\text { money and papers and all reaci" }\end{array}$ \\
\hline $\begin{array}{l}\text { Medication and } \\
\text { Vaccination }\end{array}$ & $\begin{array}{l}2 \\
3\end{array}$ & 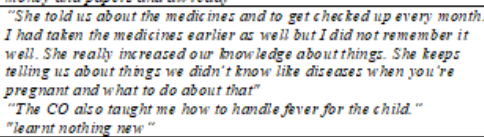 \\
\hline
\end{tabular}

Perceived causes of non-compliance

These are the responses of what the beneficiaries perceived as reasons they could not comply to orders by SNEHA or the medical providers, these are completely based on their perception of their own barriers.

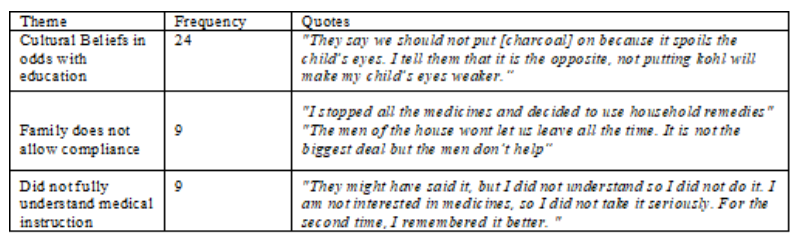

Perceived needs from SNEHA

Almost all respondents had a positive view of the organization, thus they were asked what else the organization could do for them.

\begin{tabular}{|c|c|c|}
\hline \begin{tabular}{|l|} 
Theme \\
\end{tabular} & \begin{tabular}{|l} 
Frequency \\
\end{tabular} & Quotes \\
\hline $\begin{array}{l}\text { Nothing new, like } \\
\text { the program the } \\
\text { way it is }\end{array}$ & 13 & $\begin{array}{l}\text { "I don't know what else they could do. But whatever information } \\
\text { they provide I will happity listen to it" }\end{array}$ \\
\hline $\begin{array}{l}\text { Need more help } \\
\text { with hospitals }\end{array}$ & 7 & $\begin{array}{l}\text { "I want to brow more about what to do when the child is sick. Wha } \\
\text { to do when the child has fever in the night and there is an } \\
\text { emergency, how to handle that." }\end{array}$ \\
\hline $\begin{array}{l}\text { More hygiene } \\
\text { information }\end{array}$ & 5 & $\begin{array}{l}\text { "I think we need to know how to clean the house when there is a } \\
\text { little kid, and information about how the community and the famity } \\
\text { should deal with kids in a sanitary manner." }\end{array}$ \\
\hline \begin{tabular}{|l|} 
More family \\
Planning \\
information
\end{tabular} & 2 & $\begin{array}{l}\text { "I just want to know how to not have any more kids. I am done with } \\
\text { it. Iam scared of copper Tand I am worried the injections mey not } \\
\text { suit me. My husband will be the one getting meds, but I need him to } \\
\text { get convinced first." }\end{array}$ \\
\hline
\end{tabular}

\section{Issues with Hospital Systems}

Since many mothers could not always visit the hospitals or did not like their experiences at the hospital, I asked about the reasons there were negative experiences at the hospital, and the following are the themes of responses I got. 


\begin{tabular}{|c|c|c|}
\hline Theme & Frequency & Quotes \\
\hline $\begin{array}{l}\text { Bad quality and } \\
\text { lack of resources }\end{array}$ & 11 & 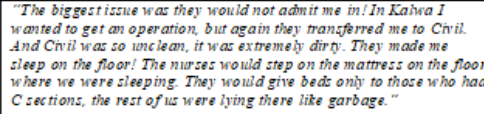 \\
\hline $\begin{array}{l}\text { Bad treatment by } \\
\text { staff }\end{array}$ & 9 & $\begin{array}{l}\text { "During my first pregnancy, I would go to the hospital and all they } \\
\text { would do is check me and send me home, they didn't tell me } \\
\text { any thing. I did not think they heiped me." }\end{array}$ \\
\hline $\begin{array}{l}\text { Access and } \\
\text { distance }\end{array}$ & 7 & 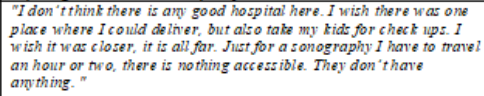 \\
\hline Cost & 7 & "They charged me for my sonography and for blood tests." \\
\hline $\begin{array}{l}\text { Issues with time } \\
\text { and scheduling }\end{array}$ & 4 & $\begin{array}{l}\text { "Everything takes longer there, becalise there are so many people. } \\
\text { Tre would be waiting in bong lines for everything, } x \text { rays and all of } \\
\text { that" }\end{array}$ \\
\hline
\end{tabular}

Qualitative Findings and Discussion

Part 1: Education Compliance

1) Medication

Medication education for expectant mothers includes taking the daily oral iron and folic acid supplements with 30 $\mathrm{mg}$ to $60 \mathrm{mg}$ of elemental iron and $400 \mu \mathrm{g}(0.4 \mathrm{mg})$ folic acid to prevent maternal anemia, and taking oral calcium supplements to be taken twice a day (total $1 \mathrm{~g}$ calcium/day) starting from 14 weeks of pregnancy up to six months postpartum. ${ }^{\text {xii }}$ The community organizers of SNEHA make it a point to demonstrate the importance of calcium and iron supplements through their conversations with the mothers and visual aids that explains the importance of micronutrients. As the results stated there was almost $50 \%$ compliance to medication information, which leads us to question such a large divide. Compliance was associated with more $\mathrm{CO}$ visits (7.69 for compliers and 4.66 for non-compliers). It is easier for community organizers to keep track of medication compliance and observe continued compliance with more visits. They can track premature cessation of supplements and can then spend more time educating the expectant mother on the importance of the supplements.

Expectant mothers with previous children tend to not comply to medication schedules. In interviews, women who did not comply before stated that "if I didn't do it last time and nothing went wrong, why now?" This was an observation for many non-compliant mothers. "Even after that I did not take calcium pills, it is my third baby and I don't think I had to take

The common trend for medication compliance was partial compliance, which was related to community organizer intervention, multiple mothers started taking medication after they met the $\mathrm{CO}$ or after the $\mathrm{CO}$ took them to the hospital to physically get the medication, confirming the community organizer importance for pre-natal compliance. Within partial compliance, the common causes for premature discontinuance were the expectant mother not feeling 'well' after taking medication or not understanding why the medication was needed in the first place. The common argument is that the not feeling 'well' part of the argument may not be directly related to the medication in the first place and could be just because of the pregnancy, more education about the importance of micronutrients could help alleviate these issues. Even mothers who were compliant, were not always sure about why the medicines were important and took them because the $\mathrm{CO}$ or the doctor asked them to, while there was no study of differences between compliers who did not understand the positive effects of the medication, it does not underscore the importance of detailed education about intervention.
2) Breastfeeding

One of SNEHA's goals of the maternal and neonatal health program is to increase the early initiation of breastfeeding: proportion of children put to the breast within 1 hour of birth and promote exclusive breastfeeding under 6 months, increasing the proportion of infants aged less than 6 months receive only breast milk on all days. ${ }^{\text {iii }}$ Six-month exclusive breastfeeding was observed in $68.8 \%$ of respondents. The non-compliers did tend to initiate breastfeeding but stopped before month 6 or did not do it exclusively. Compliers in this case had fewer children than non-compliers. The common cause of noncompliance in multiple children household was (a) difficult to find time to breastfeed the child due to management of many children, or (b) more than one child needed breastfeeding and the mother felt that she did not produce enough milk.

The non-compliers for breastfeeding excluded any mother who did not breastfeed at least once under SNEHA's educational intervention program, with the least time being 3 months and the most being 5 months. There are a few reasons that breastfeeding does not seem to be a difficult behavior to induce compliance for (1) culturally mothers are taught to breastfeed children and observe breastfeeding in many generations and family members within their own community. (2) community organizers can spend time with the mothers in their home to train them with lactation activities and observe the mother while feeding and help them make changes with their position. This creates a dynamic learning atmosphere for the mother with constant monthly training for her. Lastly, breastfeeding educational drives are very common in all Indian maternity hospitals, thus mothers who gave birth in an institution already received breastfeeding education before they got home with the baby for the first time.

The main cause of non-compliance was the mother feeling that she does not produce enough milk. Community organizers addressed this issue by advising mothers to see a medical provider, take more calcium supplements to increase lactation and counseled them to reduce stress which could affect milk production. When the community organizer stops visiting the mother after the first few months of birth, the mother becomes more likely to stop breastfeeding. The $\mathrm{CO}$ does not ever completely cut of visits for a family. The mother can expect a visit from the community organizer occasionally after the child turns 4-5 months as well, leading to promotion of observance of good practices in case of future meeting with the community organizer.

Similar to increased medication compliance, increased breastfeeding compliance could be achieved by frequenting mother's homes for a few months post-partum until exclusive breastfeeding is required, and to provide referrals and educational support about ways to optimize feeding and manage issues of lack of lactation postpartum.

\section{3) Vaccination}

The Government of India has a comprehensive list of vaccines required to be taken by children until the age of 18 . These checklists are provided to the expectant mother upon her first prenatal checkup and then again post birth. The following table is a version of what is provided to all patients as a part of public hospital education in Mumbai. 


\begin{tabular}{|l|l|}
\hline Age & Vaccines \\
\hline Birth & BCG, OPV (for institutional deliveries) \\
6 weeks & DTwP1, OPV1, HepB1, Hib1ss (BCG if not given at birth) \\
10 weeks & DTwP2, OPV2, HepB2, Hib2 \\
14 weeks & DTwP3, POV3, HepB3, Hib3 \\
$9-12$ months & Measles \\
$16-24$ months & DTwP B1, OPV4, MMR \\
$5-6$ years & DTwP \\
10 years & TT** \\
16 years & TT \\
Pregnant women & TT1 (early in pregnancy) \\
& TT2 (1 month later) \\
Vitamin A & TT booster (if vaccinated in past 3 years) \\
\hline
\end{tabular}

Figure 1. National Immunization Schedule: as provided by the Ministry of Health in India ${ }^{\text {xiv }}$

Vaccination compliance in the beneficiaries interviewed was relatively high, where $88.2 \%$ of the respondents complied with the vaccination list completely as provided by the government and SNEHA. Almost all the mothers had access to regular vaccination due to the monthly visits of hospital staff from small health posts in their area. These staff members would have a daylong camp at an easily accessible location in every community. These locations were usually temples, mosques, or a central grocery store.

Mothers who had more children (2.75) showed more compliance to vaccines than first birth mothers. One of the main reasons for this was knowledge about the location. Several first-time mothers did not know about the monthly slum vaccines programs and would go all the way to the health post or the maternity home to get the vaccines. In contrast, experienced mothers knew about all the programs in detail and would schedule their children's vaccines on the monthly visit schedule. While most mothers had positive things to say about the health post workers, few mothers had complaints about them such as 'when I go there, they are not there' or 'I never know when they will come or leave', pointing to a need to increase awareness about the times and schedules of these visits to prevent missed vaccination doses due to simple logistic issues.

Beyond this, the lack of maternal health literacy is another reason of non-compliance. A non-compliant mother of multiple children said, 'I think they are always sick because of vaccines. I gave it once and then my kid got sick, then I stopped' showing the lack of understanding of side effects of certain vaccines that cause temporary physical issues like pain, fever and weakness. Increased education about these side effects as well as the importance of vaccines could prevent missed dosages of vaccines.

The essential factor of compliance for vaccination can be linked to the monthly visits of the health post staff to the vulnerable slum communities providing door-to-door reminders and vaccines. It can be argued that this high level of compliance is not related to an increased understanding of vaccination and knowledge of health promoting behaviors. That may be true since there is no way to prove mother's selfefficacy or self-empowering decisions made by the mother to use preventative methods for the infant. A combination of the current governmental door-to-door vaccine program and an increased focus on understanding the positives of vaccination by SNEHA's educational intervention could possibly be the ideal way to create a sense of complete empowerment about health.

\section{4) Cultural}

Cultural compliance is a complicated concept since it is based on the beliefs of one's family and community. It would require the community organizer's use of educational intervention to attempt to change the belief system of the expectant mother. First it is important to go over the beliefs that are considered medically harmful by the medical community and why they need to be changed to improve the overall health condition of the infant. One of the practices of this belief system is the use of Kohl or 'kajal' that is a charcoal based product. Many Indian cultures believe this product needs to be applied around the eyes of an infant. The common erroneous belief is that the application of kohl keeps the eyes cool and clean, improves and strengthens vision. Religiously, it is believed to ward off evil spirits. ${ }^{\mathrm{xv}}$ The main issue with kohl is that it contains high levels of lead, enough for it to be banned in the United States by the FDA. The chemical contents of kohl, that includes galena or Lead(II) Sulfide (PbS), minium or Lead(IV) Oxide $\left(\mathrm{Pb}_{3} \mathrm{O}_{4}\right)$, amorphous carbon, magnetite or Iron Oxide $\left(\mathrm{Fe}_{3} \mathrm{O}_{4}\right)$, and zincite or Zinc Oxide ( $\mathrm{ZnO}$ ) whose prolonged application may cause excessive lead storage in the body, affecting the brain and bone marrow, causing convulsions and anemia. ${ }^{x v i}$ In addition to the product itself the caregiver application is not always sanitary, this could be because of dirty fingernails, sharp objects used to apply kohl and unclean methods of removal.

The second most common issue that deviates from recommended medical practices is the use of home-based medicine, which may not be as effective in turn potentially causing harm. Some of these remedies can be harmful to the infant like giving the infant water that is not pre-boiled. Oil massages for infants are a common practice in India, while the actual oil on the body is not necessarily an issue, in fact some can have benefits for the skin like better thermoregulation or prevention of dry skin, the method of the massage can be very harmful. Application issues like the use of impure oil and too much pressure during the massage can cause injury to the internal organs and the skin of the infant. ${ }^{\text {xvii. }}$.

There was $81.3 \%$ non-compliance after education against harmful cultural practices and $18.8 \%$ compliance, which is relatively much lower. To ensure compliance against these practices an increase in the average number of $\mathrm{CO}$ visits was needed from $5.3 \mathrm{CO}$ visits to $7.2 \mathrm{CO}$ visits. Non-compliers had 5.3 CO visits and compliers had 7.2 CO visits. In addition to the more number of visits, compliers also had an earlier start in intervention of the SNEHA educational program. The number of educational visits by the community organizer is very important in determining the level of cultural compliance, the visits can ensure continued education and follow up for the mother.

Unlike the previous compliance issues that are based on lack of understanding, these are very much rooted in long standing cultural beliefs and a level of mistrust in the medical system when it comes to prescribing modern practices. A noncompliant mother challenged education by saying, 'they say we should not put kohl on because it spoils the child's eyes. I tell them that it is the opposite, not putting kohl will make my 
child's eyes weaker.' showing that even with the intervention the strong cultural family belief will prevent changes in behavior. Some who complied did so due to the negative effects they observed in person like watering of the child's eyes, rashes on the infant's bodies and excessive irritation of the infant. Thus, purely education by intervention was not enough to change minds and that a more comprehensive method is needed to make sure better methods of education and follow up can be used.

Some compliers said while they stopped continuing the harmful cultural practices they did not necessarily understand why it was bad and tend to give reasons like 'my family has done it', 'I wasn't affected by it' and 'my parents wont like it'. Since compliers had more community organizer visits during pregnancy and during follow up, as well as an earlier start of educational intervention, there is proof to believe that a similar model of continued early intervention can help to improve compliance against harmful cultural practices.

The method adopted by SNEHA is one that engages community organizers that are from a similar cultural, socioeconomic and religious background to avoid problems of speaking down to communities and pushing a western medical approach with communities. A similar model can be used by medical providers in health posts, maternity homes and tertiary hospitals to bring up these concerns early on in a way that is not demeaning to the patient's culture with a culturally competent trainer. The culturally competent trainer can aid the SNEHA CO's by continuing follow up during any medical visit for the infant. For the improvement of compliance, a method already used by a few community organizers can be expanded; this includes cultural compliance education for the entire family. This form of intervention could be used to educate the family decision makers such as mother in law, husbands and other family elders in hopes to have a positive effect. In addition, family elders should be provided with proof of efficacy of modern medical methods and dangers of traditional methods, to prevent forcing of practices by them to the mother of the child. There must be a focus on understanding and not just providing information as a part of cultural interventions.

\section{Society for Nutrition Education and Health Action (SNEHA) \\ i) Perceived Benefits \\ All the participants interviewed had a generally positive} opinion of SNEHA and its community organizers. A lot of them did not necessarily know the organization by name, but by the association it had to the community organizer who they referred to as didi (sister), bhabi (sister-in-law) or tai (aunt), showing the familial relationship that was developed between the $\mathrm{CO}$ and the mother. In most cases, when asked about what they learn from SNEHA, the question had to be converted to what they learnt from the $\mathrm{CO}$ who oversaw their community to get a better and complete response. This close relationship between the $\mathrm{CO}$ and mother is exactly how the organization planned it. SNEHA believes that their COs have a relationship with the mothers like a relative and a friend. Some mothers confessed that they confided in them rather than their own family, community or other group members. ${ }^{\text {xviii }}$ The COs are asked to maintain meaningful relationships with the women through friendship and by demonstrating a genuine interest in their lives and wellbeing, in contrast to other organizations or governmental reforms where the community workers stay at the door and do not always engage in friendly non-education related conversation with the community residents.

More compliance was observed in mothers who had a long-term relationship with the $\mathrm{CO}$, than those whose $\mathrm{CO}$ changed either postpartum or during pregnancy as the new relationship was more difficult to establish.

In this entire study, the strongest observed relationship was the time spent by the community organizer with the participant and level of compliance, making the community organizer the crucial piece in the maternal and infant health improvement system of the organization. Increases in compliance would be observed with stronger relationships between the community organizers and participant by early initiation of meetings and increased prenatal and postpartum follow up. There could be ways to improve the compliance of medical instruction if a linkage is created between the community organizer and the medical system. This could include $\mathrm{CO}$ accompanying mothers during medical visits both prenatally and antenatally, increased focus on educating mothers the about importance of medical checkups or working with the hospitals to improve quality of care.

\section{ii) Perceived needs}

The major need identified was wanting more information about disease management for their infants and issues with the hospital system in the country. These concerns are very closely related to the general lack of trust the community has in the hospital system that they do not always feel empowered to visit public hospitals for illnesses that they perceive can be treated at home. While this was not a directly identified need by the respondent, there is a need to improve the relationship between the community and the medical systems since the negative perceptions of the public run hospitals are related to the lack of compliance to medical instruction and fewer than recommended number of medical checkups.

\section{Quality of Care:}

All but 3 respondents had a negative perception of the medical system due to previous negative experiences with the hospital. The concerns that mothers had, ranged from bad quality doctors, lack of facilities in the hospital and bad referral links. Two of the respondents shared stories of being asked to visit another hospital right before their scheduled delivery because the maternity home was not equipped to deal with $\mathrm{C}$ section deliveries or long labor hours.

Six respondents refused to visit the health post, which is 10-20 minutes away from each neighborhood because they perceived the health post to be 'incomplete', 'dirty', or 'not equipped'. A previous study conducted by Das et al., 2010 by the organization has also shown that the main reason of lack of medical care compliance is due to the poor behavior of staff and poor opinion of the quality of care at institutions. ${ }^{\text {xix }}$

Respondents have complained about lack of respect they feel from the doctors and nurses at public facilities in comparison to private facilities, this could be because public hospitals are overworked and the residents and interns are underpaid for the level of work they do. Private hospitals need payment thus have better paid doctors and more regulated service provision but are more expensive than any public facility. Mothers in the communities who can afford private hospitals commit to those and refuse to go back to the public hospitals due to previous experiences there. Respondents who 
moved to private hospitals claim that while expensive, it was worth it because they were better treated and cared for.

The COs at SNEHA can accompany mothers during a few of these trips to ensure that they start attending their medical appointments and observe the treatment by staff. Secondly, SNEHA works with health posts and referral systems to improve the quality of referrals, and quantity and quality of services provided by health posts. They can continue this work keeping in mind the complaints presented by mothers to the COs and by constant tracking of health posts to observe maintenance of the services. The quality maintenance of health posts may be beyond the work of community organizers, but can be handled by program managers and other managers within SNEHA who have more say in the medical community.

\section{Access and Distance:}

All the respondents had a health post within 10-minute walking distance from their house. Distance was not a huge problem for the access of care to mothers, the problems came in once the patient got there, all the respondents who went to the public clinics had complains about long waiting hours which were unpredictable and deleterious to their schedules.

A previous study on Mumbai's urban slums found similar problems with $87.3 \%$ of users in the opinion waiting time in the government health facility are more than 2 hours. ${ }^{x}$ The major access issue is that mothers do not know what resources are free and what they must pay for, with some respondents being surprised that they must pay for sonograms and blood tests. These unexpected costs lead to confusion for the mother and can cause lack of compliance of continued visits or change in the level of trust in the institutions.

There needs to be a clear exchange of information between the hospital and the community about payments and schedules. CO's can be trained by SNEHA about hospital practices so they can prepare the mother for the medical visits. Medical providers can aid by making their costs clear and try to provide an appointment based system instead of a first come first serve system, this can be hard due to the sheer number of patients they get daily and the difficulty in implementing such a scheduling system in an underfunded tertiary medical hospital.

\section{Limitations:}

The main limitation in the study is the small sample size of 34 beneficiaries that were interviewed as they may not have provided a complete view of the issues faced in compliance of the population managed by SNEHA. Secondly, there are chances of the study being biased since the participants were introduced to the interviewer by the SNEHA community organizer which might have led to answers that show a positive opinion of the organization due to the method of first contact. Since only certain communities in the municipality of Thane Municipal Corporation within Mumbai were surveyed the results might be skewed towards their opinion of the organization and the medical system.

Lastly, there might have been fear of revealing details about non-compliance due to worries about ways it could affect their future relationship with the organization, even though the informed consent form made it clear that there would be complete anonymity in all the interviews.

\section{Conclusions and Recommendations}

The level of maternal compliance in SNEHA's intervention program is closely related to the number of visits and the advent of meetings with the community organizers at SNEHA. This relationship is based on the close relationship the expectant mothers feel with the $\mathrm{CO}$ who tend to come from a similar sociocultural background as the community the mother resides in. The best way to increase the level of compliance for the participants is for the organization to utilize the relationship that the COs have with the families and the community. The main problems in compliance faced by the beneficiaries is compliance of educational intervention against harmful cultural practices and medical check-ups due to the negative perceptions of the hospital. The recommendations explained here focus on a two-pronged approach, one for the organization to find ways to increase the community organizer involvement to improve cultural and medical compliance, and to hospital systems to expunge the negative perceptions that surround them.

Recommendations for The Society of Nutrition Education and Health Action (SNEHA):

- Increase CO visits for mothers in larger families to ensure cultural compliance

- Catch up visits for expectant mothers whose first visit was later than 3 months to maintain an average of $6-8$ total prenatal visits.

- Service to have $\mathrm{CO}$ go with expectant mother for a hospital check up

- Focus on improving compliance by involving elder or decision-making family members in the educational process

- Using the $\mathrm{CO}$ as a link to continue education on hospital timings, requirements and needs.

- Monthly catch up with mother's post birth to observe compliance

- SNEHA to continue work with health posts and maternity homes to monitor quality of care and making sure they have the needed equipment 


\section{References:}

i "Maternal Health," UNICEF, http://unicef.in/Whatwedo/1/Maternal-Health.

${ }^{\text {ii }}$ Kranti S. Vora et al., "Maternal Health Situation in India: A Case Study," Journal of Health, Population and Nutrition 27, no. 2 (April 15, 2009).

iii Neena Shah More et al., "Community Mobilization in Mumbai Slums to Improve Perinatal Care and Outcomes: A Cluster Randomized Controlled Trial," PLoS Medicine 9, no. 7 (July 03, 2012).

${ }^{\text {iv }}$ Glyn Alcock et al., "Examining inequalities in uptake of maternal health care and choice of provider in underserved urban areas of Mumbai, India: a mixed methods study," BMC Pregnancy and Childbirth 15, no. 1 (September 28, 2015).

${ }^{\mathrm{v}} \mathrm{h}$ Kranti S. Vora et al., "Maternal Health Situation in India: A Case Study," Journal of Health, Population and Nutrition 27, no. 2 (April 15, 2009).

${ }^{\mathrm{vi}}$ Linda Sanneving et al., "Inequity in India: the case of maternal and reproductive health," Global Health Action 6, no. 1 (April 02, 2013),

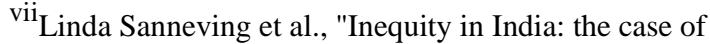
maternal and reproductive health," Global Health Action 6, no. 1 (April 02, 2013).

viii Ibid

ix Kranti S. Vora et al., "Maternal Health Situation in India: A Case Study," Journal of Health, Population and Nutrition 27, no. 2 (April 15, 2009).

x "Prenatal care and tests," Ministry of Health and Family Affairs: Women's Health, February 01, 2017, , https://www.womenshealth.gov/pregnancy/youre-pregnantnow-what/prenatal-care-and-tests.

xi "Pregnancy," National Health Portal Of India, July 05, 2016, , https://www.nhp.gov.in/healthlyliving/pregnancy.
xiiGovernment of India, Ministry of Health \& Family Welfare, Maternal Health Division, National Guidelines for Calcium Supplementation During Pregnancy and Lactation(National Health Mission, 2014).

xiii Neena Shah More et al., "Community Mobilization in Mumbai Slums to Improve Perinatal Care and Outcomes: A Cluster Randomized Controlled Trial," PLoS Medicine 9, no. 7 (July 03, 2012),

xiv "Universal Immunization Programme (UIP)," National Health Portal Of India, May 08, 2015, https:/www.nhp.gov.in/universal-immunization-programmeuip_pg.

${ }^{x v}$ Anup Mohta, "Kajal (Kohl) - A dangerous cosmetic," Oman Journal of Ophthalmology 3, no. 2 (May \& june 2010): 100, doi:10.4103/0974-620x.64242.

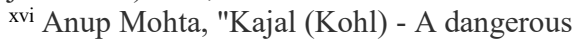
cosmetic," Oman Journal of Ophthalmology 3, no. 2 (May \& june 2010): 100, doi:10.4103/0974-620x.64242.

xvii L. C. Mullany, "Traditional Massage of Newborns in Nepal: Implications for Trials of Improved Practice," Journal of Tropical Pediatrics 51, no. 2 (January 01, 2005): 84, doi:10.1093/tropej/fmh083.

xviii Glyn A. Alcock et al., "Community-based health programmes: role perceptions and experiences of female peer facilitators in Mumbai's urban slums," Health Education Research 24, no. 6 (June 03, 2009): , doi:10.1093/her/cyp038.

xix Sushmita Das et al., "Prospective study of determinants and costs of home births in Mumbai slums," BMC Pregnancy and Childbirth 10, no. 1 (April 30, 2010): 83, doi:10.1186/14712393-10-38.

${ }^{x x}$ Palaniappan Marimuthu et al., "Perceptions on Public Health Facilities by Slum Dwellers in the Metropolitan Cities of India," Health 08, no. 01 (January 25, 2016): 94, doi:10.4236/health.2016.81011. 